CLINICAL STUDY

\title{
The estimation of selected endogenous anticoagulation system parameters in patients with subclinical Cushing's syndrome
}

\author{
Renata Świątkowska-Stodulska, Sonia Kaniuka-Jakubowska, Piotr Wiśniewski, Anna Skibowska-Bielińska ${ }^{1}$ \\ and Krzysztof Sworczak \\ Department of Endocrinology and Internal Medicine, Medical University of Gdańsk, Ul. Dębinki 7, 80-952 Gdańsk, Poland and ${ }^{1}$ General Clinical \\ Laboratory, Clinical University Centre, Gdańsk, Poland
}

(Correspondence should be addressed to R Światkowska-Stodulska; Email: rensto@gumed.edu.pl)

\begin{abstract}
Objective: An increased tendency towards thromboembolic events is observed in patients with Cushing's syndrome. There are much fewer publications available about thromboembolic complications in patients with subclinical Cushing's syndrome (SCS). Therefore, a question arises whether hemostatic disturbances appear in this particular disease phase.

Aim of study: Estimation of protein C (PC), free protein S (FPS), antithrombin (AT) activity, thrombomodulin (TM) concentration and activated PC resistance (APCR) in patients with SCS.

Materials and methods: We studied 35 patients with SCS. The control group consisted of 33 healthy volunteers. The activity of PC, AT, FPS, APCR and the concentration of TM was estimated in all representatives.

Results: The comparison of the examined coagulation parameters between the patients with SCS and the healthy individuals revealed significantly higher mean PC activity and mean FPS activity in the SCS group. Mean TM concentration was significantly lower in patients with SCS compared with the control group. The differences in APCR and AT activity were not significant. We did not prove any statistically significant correlations between the examined coagulation parameters and hormonal parameters. We did not find any correlation between the concentration of cortisol and basic coagulation parameters such as international normalized ratio, activated partial thromboplastin time or fibrinogen in the group with SCS either.

Conclusions: The patients with SCS present disturbances in endogenous anticoagulation system defined as PC, FPS activity and TM concentration. This finding suggests an impact of mild autonomic cortisol overproduction on coagulation system.
\end{abstract}

European Journal of Endocrinology 165 865-871

\section{Introduction}

Endocrinopathies can variously modify coagulation and fibrinolysis mechanisms. Glucocorticoids are the group of hormones that are thought to have a particularly strong impact on the hemostasis balance. An increased tendency towards thromboembolic events is observed both in patients with endogenous hypercortisolemia and the ones treated with steroids (1-4). Epidemiological studies show that the incidence of thromboembolic complications in patients suffering from hypercortisolemia is fourfold higher than in a population without hormonal disturbances $(1,2,5)$. The outcome of the procoagulation activity of this group of steroids results from a direct influence of hypercortisolemia on particular elements of coagulation and fibrinolysis systems as well as from the pathology of hemostasis occurring in metabolic disturbances that develop in this endocrinopathy. An increased concentration of plasma coagulation factors, especially von
Willebrand factor (vWF), VIII, IX or fibrinogen, was repeatedly confirmed in patients with hypercortisolemia $(5,6-12)$. There are also reports about the indirect impact of hypercortisolemia on thrombocytes activity (10). As mentioned above, hypercortisolemia results in fibrinolysis inhibition, mainly through its influence on the concentration of plasminogen activator inhibitor-1 (PAI-1) that expresses the highest affinity with plasminogen activators (PAI) $(13,14)$.

The studies estimating the hemostasis system and confirming an increased prothrombotic risk in patients with Cushing's syndrome are quite frequent. There are, undoubtedly, much fewer publications available about thromboembolic complications in patients with subclinical Cushing's syndrome (SCS). It probably results from the lack of precise diagnostic hormonal criteria for SCS. No matter which test has been chosen to estimate hypercortisolemia and what cortisol concentration in dynamic tests is, there is a definition which says that in patients with SCS we observe an 
autonomous production of glucocorticoids without typical clinical symptoms of hypercortisolemia. This pathological cortisol production, which results in some suppression of the pituitary-hypothalamus axis, is observed in 5-20\% of patients with incidentally diagnosed adrenal tumours (incidentalomas) (15-20). A review of currently available literature reveals a sole report estimating only three basic parameters of the coagulation system in patients with SCS (21).

Therefore, a question arises whether coagulation disturbances, which increase the risk of development of thromboembolic complications, appear in this particular disease phase. A review of the literature does not give an answer to this question. Particularly, the issue of endogenous anticoagulation system is vague, as activity in patients with SCS has not been estimated yet. This problem seems to be of major importance for making the decision to determine whether and when an anticoagulant prophylaxis should be initiated in patients with hypercortisolemia and for establishing additional indications for surgical treatment of the incidentally diagnosed adrenal tumours.

\section{Aim of study}

Estimation of protein C (PC), free protein S (FPS), antithrombin (AT) activity, thrombomodulin (TM) plasma concentration and activated PC resistance (APCR) in patients with SCS.

\section{Materials and methods}

In this cross-sectional study, we studied 35 patients ( 25 women and ten men with mean age $56.0 \pm 15.0$ years) hospitalised in the Department of Endocrinology and Internal Medicine, The Medical University of Gdańsk, who were diagnosed with SCS based on the hormonal diagnostics of an adrenal tumour. Those patients were selected from the group of 200 patients with adrenal tumours incidentally diagnosed by computed tomography examination, who had undergone hormonal diagnosis. The study took 3 years to complete. Patients with an acute or chronic symptomatic infection, neoplasm, systemic connective tissue disease, diabetic complications, features of kidney and liver failure, women using contraception or hormone replacement therapy, patients recovering from a thromboembolic episode in last 6 months or taking oral anticoagulants were excluded from the study.

The diagnosis of SCS was made on the basis of lack of suppression of serum cortisol levels after an overnight $1 \mathrm{mg}$ dexamethasone test $(>50 \mathrm{nmol} / \mathrm{l}=1.8 \mu \mathrm{g} / \mathrm{dl})$ and at least one of the following criteria: disturbed diurnal cortisol rhythm (serum cortisol at 2400:0800 h \%ratio $>50 \%$ ), decreased morning ACTH level $(\leq 10 \mathrm{pg} / \mathrm{ml})$ or increased $24 \mathrm{~h}$ urinary excretion of cortisol. None of the patients could meet the criteria of cortisol suppression using the dexamethasone test. The analysis of other hormonal divergences in the estimated group of patients revealed that 20 of them presented diurnal cortisol rhythm disturbances, 15 had their ACTH concentration suppressed and in nine we assessed an increased cortisol level in $24 \mathrm{~h}$ urine (but in no cases it exceeded the reference value by more than twofold). In the patients, we conducted a low-dose dexamethasone test ( $0.5 \mathrm{mg}$ orally every $6 \mathrm{~h}$ for 2 days), which confirmed the lack of suppression of serum cortisol levels $(>50 \mathrm{nmol} / \mathrm{l}=1.8 \mu \mathrm{g} / \mathrm{dl})$ in all of them. A complete physical examination was performed in all patients. According to the definition of SCS, none of the patients included in the study presented specific clinical signs of glucocorticoid hormone excess like: moon face, buffalo hump, truncal obesity with thin limbs and proximal myopathy or purple striae $(18,20,21)$.

All hormonal assays were performed in the same laboratory with standard laboratory kits. A solid phase, two-site sequential chemiluminescent immunometric assay (Immulite 1000 ACTH, Siemens Healthcare Diagnostics, Llanberis, Gwynedd, UK), was used to measure plasma levels of ACTH. The sensitivity for ACTH assays is $10 \mathrm{pg} / \mathrm{ml}$, which was the minimum value that can be estimated with reagents used in this study. Calibration range for this method is $10-1250 \mathrm{pg} / \mathrm{ml}$. Samples with values below sensitivity threshold were defined as $<10 \mathrm{pg} / \mathrm{ml}$.

Serum and urine levels of cortisol were measured using a chemiluminescent microparticle immunoassay (Architect Cortisol Reagent Kit, Abbott Laboratories Diagnostics Division).

For the metabolic disturbances, assessment of blood pressure and anthropometric measurements such as weight and height were evaluated in all patients. On the basis of those measurements body mass index (BMI) was calculated (body weight divided by the square of height). In addition, the following biochemical parameters: lipidogram (total cholesterol, triglycerides, HDL cholesterol and LDL cholesterol), fasting glucose and oral glucose tolerance test, were estimated using routine procedures.

In the investigated group, 13 patients (37\%) were overweight or obese (mean BMI $27.4 \mathrm{~kg} / \mathrm{m}^{2}$ ), 20 (57\%) were either diagnosed de novo or previously treated for hypertension, $16(45.7 \%)$ fulfilled the criteria for diabetes, impaired glucose tolerance or impaired fasting glycaemia.

The control group consisted of 33 healthy volunteers: personnel of our department and members of their families (19 women and 14 men in mean age 53.3 \pm 17.7 ), who matched for BMI (mean BMI $26.9 \mathrm{~kg} / \mathrm{m}^{2}$ ). The control subjects presented complete suppression of serum cortisol levels to $<50 \mathrm{nmol} / \mathrm{l}(1.8 \mu \mathrm{g} / \mathrm{dl})$ after an overnight $1 \mathrm{mg}$ dexamethasone test. 
Blood samples were collected from the elbow vein after $30 \mathrm{~min}$ of rest in supine position, in the morning hours after overnight fasting. After centrifugation, the plasma was aliquoted into microfuge tubes frozen and stored at $-70{ }^{\circ} \mathrm{C}$ until assay.

In all subjects, the analysis of PC, FPS, AT activity, APCR and TM concentration in venous blood was determined. All assays were performed at General Clinical Laboratory of University Clinical Centre. PC and AT activity was assayed by colorimetric method with chromogenic substrate using following reagents: Berichrom Protein C and Berichrom Antithrombin III (A) (Siemens Healthcare Diagnostics, Marburg, Germany). APCR was determined performing coagulometric method with the use of ProC AcR Kit (Siemens Healthcare Diagnostics), whereas FPC activity and TM concentration were measured by ELISA using Asserachrom Thrombomodulin and Asserachrom Free Protein S (Diagnostica Stago, Asnières, France), strictly according to the producer's recommendations. In all representatives, the estimation of basic coagulation parameters, such as international normalized ratio (INR), activated partial thromboplastin time (APTT) and fibrinogen concentration, was also determined with routinely used methods.

The study plan had obtained the Ethics Committee approval and permission.

To compare the means between the examined and the control group, we used an analysis of covariance (ANCOVA). The results were adjusted for age and gender. Correlations between quantitative variables were assessed by the Spearman rank correlation method. A significance level of 0.05 was used in this study. Bonferroni-corrected $P$ values are reported, however since this study was rather exploratory than a confirmatory one and the use of Bonferroni correction is a matter of debate (22), we decided not to take this adjustment into account. All calculations were performed with the use of the Statistica 8.0 statistical package (StatSoft, Inc., Tulsa, OK, USA).

\section{Results}

The results of hormonal studies in patients with SCS are shown in Table 1. The comparison of the examined coagulation parameters between the patients with SCS and the healthy individuals is summarised in Table 2 . We observed that mean PC activity and mean FPS activity were higher in the SCS group compared with the control group and we found these differences to be statistically significant. Mean TM concentration was lower in patients with SCS compared with the control group and this difference was also found to be statistically significant. These results are depicted in Fig. 1. The differences in APCR and AT activity were not significant.
Table 1 Hormonal results in patients with SCS.

\begin{tabular}{lcc}
\hline Parameter & Value & Normal range \\
\hline Serum cortisol $(\mathrm{nmol} / \mathrm{l})$ & & \\
$\quad$ Morning & $422.9 \pm 141.8$ & $101-536$ \\
Night & $265.5 \pm 156.5$ & \\
After DST & $188.7 \pm 157.5$ & $<50$ \\
$24 \mathrm{~h}$ urinary cortisol $(\mathrm{nmol} / 24 \mathrm{~h})$ & $331.2 \pm 291.6$ & $12-486$ \\
Morning plasma ACTH $(\mathrm{pg} / \mathrm{ml})$ & $19.4 \pm 14.9$ & $15-46$ \\
DHEA-S $(\mu \mathrm{g} / \mathrm{dl})$ & $65.6 \pm 73.0$ & $35-420$ \\
\hline
\end{tabular}

${ }^{\text {aAfter }} 1 \mathrm{mg}$ dexamethasone suppression test.

We also analysed the relationship between the coagulation parameters and the hormonal parameters. There was no statistically significant correlation between FPS, PC, AT activity, APCR, TM concentration and serum cortisol levels after ingestion of $1 \mathrm{mg}$ of dexamethasone and $24 \mathrm{~h}$ urinary excretion of cortisol. We did not find any correlation between the concentration of cortisol and basic coagulation parameters such as INR, APTT or fibrinogen in the group with SCS either.

In this study, we did not reveal any statistically relevant differences in analysed parameters between women and men.

\section{Discussion}

The review of available literature reveals many studies estimating coagulation and fibrinolysis systems in patients with clinical evident hypercortisolemia $(4,6-$ 11, 23-25). However, there are only a few publications about the hemostatic system in patients with SCS, and additionally they only concern basic coagulation parameters (21). Tauchmanovà et al. (21) assessing cardiovascular risk in SCS patients revealed a considerably higher fibrinogen concentration among this group than among the normal comparison subjects, whereas prothrombin time and APTT remained without any statistically significant difference. Until now there are no publications about the activity of endogenous anticoagulation system in patients with SCS. Our study concerned among activity of PC, FPS and AT which are endogenous inhibitors of coagulation system and which activation is initiated by thrombin accumulation. Thrombin in complex with TM, which is its receptor

Table 2 Comparison of estimated parameters between SCS patients and healthy controls.

\begin{tabular}{lcccc}
\hline Parameter & SCS & Control & $\boldsymbol{P}$ & $\boldsymbol{P}^{*}$ \\
\hline FPS (\%) & $80.8 \pm 16.5$ & $69.9 \pm 11.9$ & 0.023 & 0.115 \\
PC (\%) & $150.0 \pm 28.3$ & $108.5 \pm 16.5$ & 0.000 & 0.000 \\
AT (\%) & $108.4 \pm 15.4$ & $110.1 \pm 7.6$ & 0.263 & \\
APCR & $2.9 \pm 1.1$ & $3.0 \pm 0.7$ & 0.525 & \\
TM (ng/ml) & $18.5 \pm 11.3$ & $27.2 \pm 14.8$ & 0.013 & 0.065 \\
\hline
\end{tabular}

${ }^{\star}$ Bonferroni-adjusted $P$ values. 


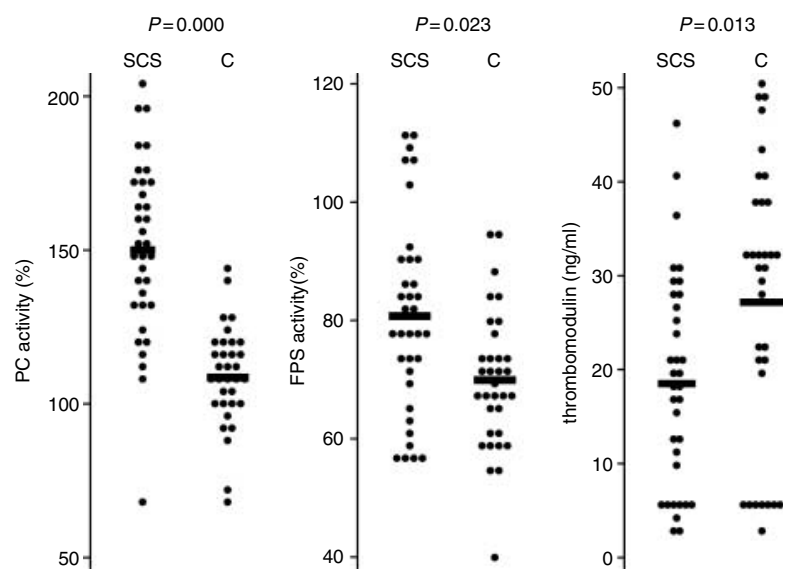

Figure 1 Observed values of FPS, PC activity and thrombomodulin concentration in patients with SCS and control group (C). Each filled circle represents a single observation. Horizontal solid lines indicate the arithmetical mean.

on the epithelium cells, through activation of PC and inhibition of PAI-1 obtains profibrinolytic and anticoagulant features. Activated PC with its cofactor PS degrades and inactivates coagulation factors $\mathrm{Va}$ and VIIIa by their partial proteolysis $(26,27)$. An important endogenous inhibitor of the coagulation system is also AT which inactivates Xa factor and thrombin, and in lesser degree, other factors such as XIIa, XIa i IXa. The deficiency of PC, PS and AT, which are inhibitors of coagulation, is an unquestionable risk factor for thromboembolic lesions development (28). In this study, we revealed a significantly higher activity of PC and FPS in patients with subclinical hypercortisolemia than in healthy volunteers. We did not observe such differences in AT activity. The lack of publications about the evaluation of these parameters in patients with SCS makes it impossible to compare our results with the relevant literature data. There are very few studies which carry out the evaluation of endogenous coagulation inhibitors in patients with clinically evident Cushing's syndrome, yet they all revealed significantly higher activity of both PC and PS and AT in patients with hypercortisolemia $(6,7,13)$. Similar observations were also made in patients with systemic lupus erythematosus treated with glucocorticoids (29). Therefore, we can assume that an increased activity of endogenous coagulation inhibitors occurs in patients with hypercortisolemia. The question arises why patients with this endocrinopathy more frequently have thromboembolic events if the activity of the anticoagulation system seems to be proper or even increased. Perhaps these changes are secondary to the increased procoagulation tendency in hypercortisolemia, resulting from the elevated concentration of plasma coagulation factors of both exogenous or endogenous coagulation system, particularly $\mathrm{V}$ and VIII factors. The increase of PC and FPS activities could be a compensatory mechanism, protecting against thrombus complications both in subclinical subjects or with clinically evident hypercortisolemia.

The next estimated parameter was plasma concentration of TM that is a specific receptor for thrombin. It is released from endothelial cell membrane when the cells are damaged; hence, it is treated as a marker of endothelial injury. In this study, we revealed significant differences in TM concentration between the group with SCS and the healthy representatives. We observed lower TM concentration in subjects with subclinical hypercortisolemia. TM is a specific receptor for thrombin and in this complex leads to the activation of PC $(26,27)$. Therefore, its plasma concentration can also be determined by the present thrombinogenesis process and the activity of anticoagulation system.

Séguin et al. (30) proved that thrombin causes a decrease in TM expression and activity in endothelium cells, which may suggest that negative feedback between the elements of the hemostasis system, upsets the balance between thrombin generation and the production of activated PC.

Hence, lower TM concentration in patients with SCS can be the result of an increased thrombin generation and PC and FPS activity in this group of patients. It also has to be emphasised that after binding to TM, thrombin loses its ability to clot fibrinogen and aggregate thrombocytes. Therefore, a low concentration of TM, which is a receptor for thrombin, can have an indirect procoagulation effect.

There is no available literature about the estimation of TM concentration or other endothelial function parameters in patients with SCS, what makes the comparison of obtained results impossible. What deserves our attention, however, is the study by Jilma et al. (31) who stated the lack of dexamethasone influence on soluble TM concentration in healthy representatives. However, those studies concerned healthy men after steroid infusion. The influence of long-lasting subclinical hypercortisolemia on TM concentration can be different.

The next estimated parameter was APCR, whose defect is also the cause of evolution of vascular changes. In $\sim 90 \%$ of cases APCR is a result of the Factor V Leiden mutation. This changed factor maintains its procoagulation activity and does not undergo proteolysis by activated PC. Apart from Factor V Leiden mutation, other revealed causes of an increased factor $\mathrm{V}$ resistance to activated PC were: a low concentration of PS or tissue factor pathway inhibitor, pregnancy, use of hormonal contraception, antiphospholipid syndrome, autoimmune connective tissue disorders with antibodies against PS or PC, which incurs their decreased concentration $(32,33)$. In our study, we did not find statistically significant differences in APCR between both analysed groups. Therefore, it seems that patients with subclinical hypercortisolemia do not present an increased factor $V$ resistance to activated PC. 
Estimating coagulation system parameters in patients with hypercortisolemia, we have to pay attention to the metabolic disturbances occurring such as obesity, diabetes mellitus or hypertension. The studies of the endogenous coagulation system parameters concern mainly obese patients and their results are equivocal. In their study, Batist et al. (34) revealed a noticeably lower activity and concentration of AT in obese patients. Great majority of researchers, however, did not confirm those results. De Pergola et al. $(35,36)$ did not find significant differences in PC and AT activity between obese and healthy men, yet in obese women they proved a substantial increase in PC activity. Those results were also confirmed by Bowles et al. (37), who revealed a positive correlation between BMI and the activity of this parameter. There are also discrepancies in literature considering TM plasma concentration in obese patients. However, most of researchers confirm a noticeably higher concentration of this glycoprotein in obese patients, especially those who met the criteria of metabolic syndrome $(38,39)$. The authors of this study selected the control group with suitable BMI to exclude the influence of obesity on the estimated parameters.

The dependence between the estimated parameters and disturbances of carbohydrate metabolism has not been completely indicated in the hitherto prevailing studies. Sumida et al. (40) did not reveal any differences in TM activity between the patients with insulindependent diabetes mellitus and healthy controls. Most studies seem to confirm an increased TM concentration or PS activity in patients with diabetic complications, especially diabetic nephropathy (41-43). Such patients were not included in our study. There are also reports according to which patients with hypertension presented an increased TM concentration in comparison with normotensive controls (44). In this study, however, we revealed statistically lower activity of TM in the group with SCS than in the healthy controls, despite hypertension in $57 \%$ of the study participants. Therefore, hypertension did not have any influence on study results.

The interpretation of the obtained results is difficult due to the lack of opportunities to compare the results with other studies. There is no comparison of the estimated parameters of coagulation system between SCS patients and clinically manifested hypercortisolemia in our study, which also imposes certain limitations. However, our results raise an issue of estimation of the hemostatic balance in patients with SCS. Up to now, there are no available publications estimating parameters investigated by our team in subjects with subclinical hypercortisolemia. Most of the investigators have concentrated on the increased risk of cardiovascular complications in this group $(21,45)$. Until now, the risk and incidence of thromboembolic events as well as recommendation for prophylactic anticoagulation therapy in patients with SCS have not been established.
The results of the presented study still leave lots of questions and need to be confirmed by further investigations with larger population and determination of other coagulation and fibrinolysis parameters. It is of especially high importance for establishing the indications for prophylactic anticoagulation in those groups of patients.

\section{Conclusions}

On the basis of the obtained results, we can conclude that in comparison with healthy controls, patients with SCS present disturbances in endogenous anticoagulation system defined as PC, FPS activity and TM concentration. This finding suggests an impact of mild autonomic cortisol overproduction on coagulation system.

\section{Declaration of interest}

The authors declare that there is no conflict of interest that could be perceived as prejudicing the impartiality of the research reported.

\section{Funding}

This work was supported by Medical University of Gdańsk funds (grant number: W 133/2008-2010).

\section{References}

1 Boscaro M, Sonino N, Scarda A, Barzon L, Fallo F, Sartori MT, Patrassi GM \& Girolami A. Anticoagulant prophylaxis markedly reduces thromboembolic complications in Cushing's syndrome. Journal of Clinical Endocrinology and Metabolism $2002 \mathbf{8 7}$ 3662-3666. (doi:10.1210/jc.87.8.3662)

2 Brotman DJ, Girod JP, Posch A, Jani JT, Patel JV, Gupta M, Lip GY, Reddy S \& Kickler TS. Effects of short-term glucocorticoids on hemostatic factors in healthy volunteers. Thrombosis Research 2006118 247-452. (doi:10.1016/j.thromres.2005. 06.006)

3 Jilma B, Cvitko T, Winter-Fabry A, Petroczi K, Quehenberger P \& Blann AD. High dose dexamethasone increases circulating P-selectin and von Willebrand factor levels in healthy men. Thrombosis and Haemostasis 200594 797-801. (doi:10.1160/ TH04-10-0652)

4 Jacoby RC, Owings JT, Ortega T, Gosselin R \& Feldman EC. Biochemical basis for the hypercoagulable state seen in Cushing syndrome. Archives of Surgery 2001136 1003-1006. (doi:10. 1001/archsurg.136.9.1003)

5 Van Zaane B, Nur E, Squizzato A, Dekkers OM, Twickler MT, Fliers E, Gerdes VE, Büller HR \& Brandjes DP. Hypercoagulable state in Cushing's syndrome: a systematic review. Journal of Clinical Endocrinology and Metabolism 200994 2743-2750. (doi:10. 1210/jc.2009-0290)

6 Kastelan D, Dusek T, Kraljevic I, Giljevic Z, Solak M, Salek SZ, Jelcic J, Aganovic I \& Korsic M. Hypercoagulability in Cushing's syndrome: the role of specific haemostatic and fibrynolytic markers. Endocrine 200936 70-74. (doi:10.1007/s12020-0099186-y)

7 Manetti L, Bogazzi F, Giovannetti C, Raffaelli V, Genovesi M, Pellegrini G, Ruocco L, Iannelli A \& Martino E. Changes in coagulation indexes and occurrence of venous thromboembolism 
in patients with Cushing's syndrome: results from a prospective study before and after surgery. European Journal of Endocrinology 2010163 783-791. (doi:10.1530/EJE-10-0583)

8 Patrassi GM, Dal Bo Zanon R, Boscaro M, Martinelli S \& Girolami A. Further studies on the hypercoagulable state of patients with Cushing's syndrome. Thrombosis and Haemostasis $198554518-520$.

9 Patrassi GM, Sartori MT, Viero ML, Scarano L, Boscaro M \& Girolami A. The fibrinolytic potential in patients with Cushing's disease: a clue to their hypercoagulable state. Blood Coagulation $\mathcal{E}$ Fibrinolysis 19923 789-793. (doi:10.1097/00001721-199212 000-00013)

10 Casonato A, Pontara E, Boscaro M, Sonino N, Sartorello F, Ferasin S \& Girolami A. Abnormalities of von Willebrand factor are also part of the prothrombotic state of Cushing's syndrome. Blood Coagulation \& Fibrinolysis 199910 145-151. (doi:10.1097/ 00001721-199904000-00006)

11 Fatti LM, Botasso B, Invitti C, Coppola R, Cavagnini F \& Mannucci PM. Markers of activation of coagulation and fibrinolysis in patient with Cushing's syndrome. Journal of Endocrinological Investigation 200023 145-150.

12 Rosenfeld BA, Faraday N, Campbell D, Dise K, Bell W \& Goldschmidt P. Hemostatic effects of stress hormone infusion. Anesthesiology 199481 1116-1126. (doi:10.1097/00000542199411000-00005)

13 Erem C, Nuhoglu I, Yilmaz M, Kocak M, Demirel A, Ucuncu O \& Onder Ersoz H. Blood coagulation and fibrinolysis in patients with Cushing's syndrome: increased plasminogen activator inhibitor-1, decreased tissue factor pathway inhibitor, and unchanged thrombin-activatable fibrinolysis inhibitor levels. Journal of Endocrinological Investigation 200932 169-174.

14 Juhan-Vague I, Alessi MC, Mavri A \& Morange PE. Plasminogen activator-1, inflammation, obesity, insulin resistance and vascular risk. Journal of Thrombosis and Haemostasis 20031 1575-1579. (doi:10.1046/j.1538-7836.2003.00279.x)

15 Terzolo M, Reimondo G, Bovio S \& Angeli A. Subclinical Cushing's syndrome. Pituitary 20047 217-223. (doi:10.1007/s11102005-4024-6)

16 Caetano MS, Silva Rdo C \& Kater CE. Increased diagnostic probability of subclinical Cushing's syndrome in a population sample of overweight adult patients with type 2 diabetes mellitus. Arquivos Brasileiros de Endocrinologia e Metabologia 200751 1118-1127. (doi:10.1590/S0004-2730200700070 0015)

17 Terzolo M, Bovio S, Reimondo G, Pia A, Osella G, Borretta G \& Angeli A. Subclinical Cushing's syndrome in adrenal incidentalomas. Endocrinology and Metabolism Clinics of North America 2005 34 423-439. (doi:10.1016/j.ecl.2005.01.008)

18 Terzolo M, Osella G, Alì A, Borretta G, Cesario F, Paccotti P \& Angeli A. Subclinical Cushing's syndrome in adrenal incidentaloma. Clinical Endocrinology 199848 89-97. (doi:10.1046/j. 1365-2265.1998.00357.x)

19 Sworczak K, Babińska A, Stanek A, Lewczuk A, SiekierskaHellman M, Błaut K, Drobińska A, Basinski A, Łachiński AJ, Czplińska-Kałas H \& Gruca Z. Clinical and histopathological evaluation of the arenal incidentaloma. Neoplasma $2001 \mathbf{4 8}$ 221-226.

20 Mazzuco TL, Bourdeau I \& Lacroix A. Adrenal incidentalomas and subclinical Cushing's syndrome: diagnosis and treatment. Current Opinion in Endocrinology, Diabetes, and Obesity 200916 203-210. (doi:10.1097/MED.0b013e32832b7043)

21 Tauchmanovà L, Rossi R, Biondi B, Pulcrano M, Nuzzo V, Palmieri EA, Fazio S \& Lombardi G. Patients with subclinical Cushing's syndrome due to adrenal adenoma have increased cardiovascular risk. Journal of Clinical Endocrinology and Metabolism 200287 4872-4878. (doi:10.1210/jc.2001-011766)

22 Nakagawa S. A farewell to Bonferroni: the problems of low statistical power and publication bias. Behavioral Ecology 200415 1044-1045. (doi:10.1093/beheco/arh107)
23 Ikkala E, Myllylä G, Pelkonen R, Rasi V, Viinikka L \& Ylikorkala O. Haemostatic parameters in Cushing's syndrome. Acta Medica Scandinavica 1985217 507-511. (doi:10.1111/j.0954-6820. 1985.tb03254.x)

24 Świątkowska-Stodulska R, Babińska A \& Sworczak K. Hypercortisolism and hemostasis. Polski Merkuriusz Lekarski 200926 $142-144$.

25 Świątkowska-Stodulska R, Babińska A \& Sworczak K. Effect of selected hormones on particular parameters of hemostasis. Wiadomosci Lekarskie 200760 390-393.

26 Kopeć M. Diverse and variable functions of thrombin. Acta Haematologica Polonica 199728 95-100.

27 Kopeć M. Progress in understanding mechanisms of blood coagulation activation. Acta Haematologica Polonica 199425 (Suppl 2) 5-13.

28 Zawilska K. Czynniki ryzyka zakrzepów tętniczych. In Zakrzepy i zatory, pp 141-151. Ed. S Łopaciuk, Warszawa (in Polish): Wydawnictwo Lekarskie PZWL, 1996.

29 Costallat LT, Ribeiro CC \& Annichino-Bazzacchi JM. Antithrombin, protein $\mathrm{S}$ and protein $\mathrm{C}$ and antiphospholipid antibodies in systemic lupus erythematosus. Sangre 199843 345-348.

30 Séguin C, Abid R, Spokes KC \& Aird WC. Thrombin downregulates thrombomodulin expression and activity in primary human endothelial cells. Endothelium 200815 143-148. (doi:10.1080/ 10623320802125508)

31 Jilma B, Blann AD, Stohlawetz P, Eichler HG, Kautzky-Willer A \& Wagner OF. Dexamethasone lowers circulating E-selectin and ICAM-1 in healthy men. Journal of Laboratory and Clinical Medicine 2000135 270-274. (doi:10.1067/mlc.2000. 105214)

32 Castoldi E \& Rosing J. APC resistance: biological basis and aquired influences. Journal of Thrombosis and Haemostasis $2009 \mathbf{8}$ 445-453. (doi:10.1111/j.1538-7836.2009.03711.x)

33 Soare AM \& Popa C. Deficiencies of protein C, A and antithrombin and activated protein $\mathrm{C}$ reasistance-their involvement in the occurrence of arterial thromboses. Journal of Medicine and Life $20103412-415$.

34 Batist G, Bothe A Jr, Bern M, Bistrian BR \& Blackburn GL. Low antithrombin III in morbid obesity: return to normal with weight reduction. Journal of Parenteral and Enteral Nutrition 19837 447-449. (doi:10.1177/0148607183007005447)

35 De Pergola G, De Mitrio V, Sciaraffia M, Pannacciulli N, Minenna A, Giorgino F, Petronelli M, Laudadio E \& Giorgino R. Lower androgenicity is associated with higher plasma levels of prothrombotic factors irrespective of age, obesity, body fat distribution, and related metabolic parameters in men. Metabolism 199746 1287-1293. (doi:10.1016/S0026-0495(97)90232-8)

36 De Pergola G, De Mitrio V, Giorgino F, Sciaraffia M, Minenna A, Di Bari L, Pannacciulli N \& Giorgino R. Increase in both prothrombotic and anti-thrombotic factors in obese premenopausal women: relationship with body fat distribution. International Journal of Obesity and Related Metabolic Disorders 199721 527535. (doi:10.1038/sj.ijo.0800435)

37 Bowles LK, Cooper JA, Howarth DJ, Miller GJ \& MacCallum PK. Associations of haemostatic variables with body mass index: a community-based study. Blood Coagulation \& Fibrinolysis 200314 569-573. (doi:10.1097/00001721-200309000-00009)

38 Rość D, Drewniak W, Kinasz-Rozycka I, Kulwas A \& Michalski A. Thrombomodulin, von Willebrand factor and tissue plasminogen activator in the blood plasma of obese women and men. Polski Merkuriusz Lekarski 200315 518-520.

39 Świątkowska-Stodulska R, Skibowska-Bielińska A, Bękowska A, Wiśniewski P \& Sworczak K. Assessment of selected haemostatic parameters in obese patients. Endokrynologia Polska $2007 \mathbf{5 8}$ 505-509.

40 Sumida Y, Wada H, Fujii M, Mori Y, Nakasaki T, Shimura M, Hiyoyama K, Yano Y, Deguchi K, Shiku H \& Adachi Y. Increased soluble fibrin monomer and soluble thrombomodulin levels in non-insulin-dependent diabetes mellitus. Blood Coagulation $\mathcal{E}$ Fibrinolysis 19978 303-307. (doi:10.1097/00001721-199707 000-00007) 
41 Gabat S, Keller C, Kempe HP, Amiral J, Ziegler R, Ritz E, Bergis KH, Wahl P \& Nawroth P. Plasma thrombomodulin: a marker for microvascular complications in diabetes mellitus. VASA. Zeitschrift für Gefässkrankheiten. Journal for VascularDiseases $1996 \mathbf{2 5}$ 233-241.

42 Reverter JL, Reverter JC, Tàssies D, Rius F, Monteagudo J, Rubiés-Prat J, Escolar G, Ordinas A \& Sanmarti A. Thrombomodulin and induced tissue factor expression on monocytes as markers of diabetic microangiopathy: a prospective study on hemostasis and lipoproteins in insulin-dependent diabetes mellitus. American Journal of Hematology $1997 \mathbf{5 6}$ 93-99. (doi:10.1002/(SICI)1096-8652(199710)56:2<93::AID-AJH4> 3.0.CO;2-W)

43 Lengyel Z, Vörös P, Tóth LK, Németh C, Kammerer L, Mihály M, Tornóci L \& Rosivall L. Urinary albumin excretion is correlated to fibrinogen levels and protein $\mathrm{S}$ activity in patients with type 1 diabetes mellitus without overt diabetic nephropathy. Wiener Klinische Wochenschrift 2004116 240-245. (doi:10.1007/ BF03041054)

44 Wojtkielewicz K, Urban M, Peczyńska J \& Głowińska B. Is soluble thrombomodulin a molecular marker of endothelial cell injury in children and adolescents with arterial hypertension? Medycyna Wieku Rozwojowego 200610 893-902.

45 Tsuki M, Tanabe E, Takagi S, Naruse M \& Takano K. Cardiovascular risk and their long-term clinical outcome in patients with subclinical cushing's syndrome. Endocrine Journal $2008 \mathbf{5 5}$ 737-745. (doi:10.1507/endocrj.K07E-177)

Received 4 May 2011

Revised version received 7 September 2011

Accepted 12 September 2011 